resembles a wind tunnel in that the hydrofoil under test is fixed and the water flows past at speeds up to 15 miles per hour. Because scaled-down hydrofoils are used, the information gained will refer to hydrofoil boats travelling at up to 100 miles per hour. The behaviour of the hydrofoils is observed by high speed ciné photography through 'Perspex' windows in the side of the channel.

The research group at Leeds which is studying hydrofoils is led jointly by Professor Boris Cole, who is head of the Department of Mechanical Engineering, and Mr P. D. Swales. They are financed by contracts worth $£ 27,000$ from the Science Research Council and the Ministry of Technology.

In particular, the channel will be used to study the behaviour of hydrofoils when air is sucked down behind the strut supporting the foil to form an air cavity around the foil itself. This phenomenon, known as "ventilation", has profound effects on the performance of the foil. Professor Cole's group has been awarded a Ministry of Technology contract to study the so-called surface-piercing hydrofoils under such ventilated conditions. Surface-piercing hydrofoils have $V$-shaped foils which rise or sink through the surface of the water according to the speed of the craft. Another class of hydrofoils has fully submerged horizontal foils, but there seems to be a wide diversity of variants.

The new facility at Leeds will also study another phenomenon affecting the performance of hydrofoilscavitation. This is the formation of vapour-filled bubbles around the foil, and occurs under certain pressure and temperature conditions. The pressure in the new water channel can be altered to influence the extent to which cavitation and ventilation occur.

Tests on models have the drawback that it is sometimes uncertain to what extent the results apply to full-size boats. The large size of the equipment at Leeds means that the extrapolation to real conditions is fairly simple.

\section{Welders Welded}

LAST week the members of the British Welding Research Association and the Institute of Welding agreed to combine forces to set up a new organization, to be called the Welding Institute. The hope is to combine the technological strength of the research association with the professional functions of the institute. Both the research association and the institute see the move as a logical development, in which the welding technologist can be backed by the full resources of the scientific work of the research association.

For those with long memories, the merger will seem like old times. The research association began life in 1946 on the basis of work done by the research council of the Institute of Welding. Now the two organizations have come together again. The new organization will have a total membership of 1,500 industrial organizations and government departments, a professional membership of 5,500 , and an annual income of $£ l$ million. The institute is hoping to make a real contribution in education, through its school of welding technology, to the training of welding engineers at all levels. Ultimately the aim is to achieve recognition of the professional qualification of welding cngineer. In addition, the institute hopes to provide better library and information services, and a continuing interest in weld- ing standards and specifications. The first director of the institute will be Dr Richard Weck, who until the merger was director of the BWRA. The institute will be governed by a council under the chairmanship of $\mathrm{Mr} \mathrm{A}$. Robert Jenkins.

\section{Animal Diseases 1967}

THE statutory return of the Ministry of Agriculture for animal diseases in Great Britain during 1967 was published last week (HMSO, ls.). The foot and mouth disease epidemic, although the worst ever in Britain, was not as widespread as the severe outbreaks in 1923 and 1924. Only eighteen counties were affected. Of the other three diseases covered by the report, outbreaks of fowl pest rose from 194 in 1966 to 198 in 1967, and outbreaks of anthrax rose from 222 in 1966 to 438 in 1967 , but the incidence of bovine tuberculosis remained low. The cost in compensation for fowl pest and tuberculosis

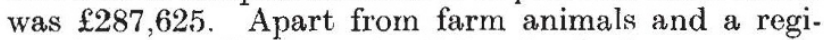
mental goat, 52 cloven-hoofed animals for zoos were imported.

\section{The Taste of Meat}

Professor M. Ingram, the director of the new ARC Meat Research Institute at Langford, near Bristol, said last week that meat probably doesn't taste as good as it did in grandmother's day, but that his new institute is going to try to put that right. High quality and mass production are usually incompatible and meat is no exception, but so very little is known about meat as such that research should make it possible to improve quality without sacrificing quantity.

The new Meat Research Institute has been built on the campus of Bristol University's Veterinary School at a total cost of about $£ 1$ million, and it now houses under one roof one hundred people, sixty of whom were doing research on meat at the SRC Low Temperature Research Station at Cambridge, the School of Agriculture at Cambridge and a Ministry of Food Laboratory in London. 'To some extent the organization of the institute reflects this. There are three divisions, the carcass and meat department, the biochemistry, histology and physiology department and the bioengineering and microbiology departments.

The carcass and meat department is basically trying to find new criteria for evaluating carcasses commercially. How much meat and how much bone is there and what is the quality of the meat? One group is exploring the anatomy of carcasses to see if any anatomical features, preferably in a commercially valueless part of the carcass, such as the shin bone, can be used as a criterion for the quality of the whole carcass. A second group is making measurements of the specific gravity of joints of meat, and another is using what is in effect a modification of echo-sounding to measure the fat and meat in pigs. Sound is reflected from fat muscle boundaries. Research is also going on into how best to slaughter animals, because a high blood content in meat might make it tougher; how to judge animals at agricultural shows-important in determining grading systems; and to decide whether carcasses can be butchered while still warm rather than waiting until rigor mortis sets in. (Hot butchering would save time and is used in salami factories in Hungary.) By far the most difficult job 